\title{
Staff and students perception of lecture capture
}

Eleanor J Dommett ${ }^{1,2 *}$, Benjamin Gardner ${ }^{1}$ and Wijnand van Tilburg ${ }^{1}$

${ }^{1}$ Department of Psychology,

Institute of Psychiatry, Psychology and Neuroscience,

King's College London,

London.

SE5 8AF

${ }^{2}$ Centre for Technology Enhanced Learning,

Waterloo Bridge Wing,

Franklin-Wilkins Building,

150 Stamford Street,

London.

SE1 9NH

${ }^{*}$ Corresponding author: Eleanor J Dommett

Telephone: +44 (0) 2078486928

Email: Eleanor.dommett@kcl.ac.uk 


\section{Abstract}

Many universities use lecture capture to record live lectures and make them available online, although this practice is not without controversy. We used an online survey to investigate perceptions of lectures and their capture in staff $(N=95)$ and students $(N=522)$. We found that they valued lectures and perceived capture differently, despite similar views on the type of learning lectures best support. Students were more positive about capture, utilising the online platform effectively. Exact use differed depending on whether students were substituting or supplementing attendance. Use of lecture capture was predicted by several factors including: demand of live lectures, attendance, and performance. Student attendance ratings were predicted by the availability of online resources and difficulty in getting to lectures, whilst staff felt only availability of online resources was critical in determining student attendance. Differing views of lectures and the importance of attendance may contribute to the different overall perceptions of lecture capture in these two groups.

\section{Highlights}

- Students value lectures more highly but perceive less need for participation

- Students perceive capture positively with little impact on the live lecture

- Use of capture is predicted by factors relating to the individual student

- Use of capture is also predicted by factors relating to the live lecture e.g. speed

- Lecture capture is one of several variables that negatively impacts attendance

\section{Key words}

Learning outcome; attendance; student performance; technical awareness 


\section{Introduction}

Lectures are engrained within Higher Education ( $\mathrm{HE})$, providing an economical approach to teaching large classes (Behr, 1988). Students value lectures highly, reporting that they feel involved in the learning process, and engage in independent thinking and problem solving during lectures (Covill, 2011). Furthermore, studies have found that lectures provide opportunities for modelling how experts approach tasks (Feldon, 2010) and allow students to build links between materials that they may not manage from reading alone (Kirkpatrick, 1990). Additionally, lectures may be considered preferable for students transitioning to university where self-confidence may actually be harmed by engaging in more active forms of learning (Burgan, 2006).

The recording of live lectures, referred to as lecture capture, is increasingly common (Deal, 2007; Evans, 2008; McGarr, 2009; Scutter, Stupans, Sawyer, \& King, 2010; Traphagan, 2005; Woo et al., 2008). This capture can be produced in several formats including i) audio only, ii) audio and slide and iii) audio, slide and video, and made available to students online. Lecture capture at our own university in all three formats using the Echo360 platform. It was rolled out in September 2015, with the capturing of lectures being the default approach and staff having to actively opt out of capture with permission from senior management if they did not wish their lectures to be captured. Once captured the recordings of all lectures are made available to students enrolled on a course via the virtual learning environment (VLE) and, therefore these are available to view for enrolled students anywhere there is internet access. Following two years of use across the university, most students and staff have experience of lecture capture, making it an appropriate time examine the perception and impact of lecture capture. 


\section{Literature Review}

The most consistent research finding on lecture capture is that students have a positive perception of it (Gosper et al., 2008; Heilesen, 2010; McGarr, 2009; O'Callaghan, Neumann, Jones, \& Creed, 2017; Pons, Walker, Hollis, \& Thomas, 2012; Traphagan, Kucsera, \& Kishi, 2010). This positivity is largely stable across student characteristics (e.g., irrespective of age, gender, enrolment mode or attendance pattern) (Gosper et al., 2010). In line with the positive perception, the availability of lecture capture has been shown to improve student satisfaction (Al-Nashash \& Gunn, 2013; Brecht \& Ogilby, 2008; Bryans Bongey, Cizadlo, \& Kalnbach, 2006; Greenberg \& Nilssen, 2009; Secker, Bond, \& Grussendorf, 2010; Toppin, 2011; Traphagan et al., 2010; Veeramani \& Bradley, 2008; Woo et al., 2008) and influence course choice (Vajoczki, Watt, Marquis, Liao, \& Vine, 2011; Watt et al., 2014).

Several studies have also investigated when and how students use lecture capture. This research reveals peaks in usage during assessment and revision periods (Brady, Wong, \& Newton, 2013; Gosper et al., 2010; Saunders \& Hutt, 2015) and show capture is used to review complex material, pick up on sections they missed in the live lecture (Gorissen, Van Bruggen, \& Jochems, 2012; Gosper et al., 2010; Groen, Quigley, \& Herry, 2016; Watt et al., 2014), make more detailed notes (Elliott \& Neal, 2016; Gosper et al., 2010; Newton, Tucker, Dawson, \& Currie, 2014; Saunders \& Hutt, 2015; Watt et al., 2014) and to take control of how they learn, particularly through self-pacing (Al-Nashash \& Gunn, 2013; Gosper et al., 2010; Newton et al., 2014; Watt et al., 2014). Perhaps unsurprisingly, use of lecture capture is particularly beneficial when the student's first language differs from that of the instruction language (Gosper et al., 2010; Groen et al., 2016; Revell, 2013; Saunders \& Hutt, 2015). 
Despite high use around assessment and revision periods, the relationship between lecture capture and academic performance is unclear. While students believe lecture capture positively impacts performance (Al-Nashash \& Gunn, 2013; Groen et al., 2016), studies using actual grades show a mixed picture with some indicating a positive relationship (Bollmeier, Wenger, \& Forinash, 2010; Francom, Ryan, \& Kariuki, 2011; Griffin, Mitchell, \& Thompson, 2009; Harrigan, 1995; McFarlin, 2008; McKinney, Dyck, \& Luber, 2009; Vajoczki, Watt, Marquis, \& Holshausen, 2010; Wiese \& Newton, 2013; Yu, Wang, \& Su, 2015) and others reporting little or no relationship between the capture and performance (Abt \& Barry, 2007; Brotherton \& Abowd, 2004; Edwards \& Clinton, 2018; Hadgu, Huynh, \& Gopalan, 2016). Additionally, even where a positive relationship is found, the effect size is variable, ranging from an increase in exam score of just $0.5 \%$ (Snowball, 2014) to 15\% (Cramer, Collins, Snider, \& Fawcett, 2007).

The association between lecture capture and performance is clearly complex, not least because of factors that may moderate the relationship, including student characteristics. For example, the relationship may be impacted by proficiency in the language in which one is taught (Molnar, 2011; Revell, 2013), gender (Williams, Aguilar-Roca, \& O’Dowd, 2016) and study year (Nordmann, Calder, Bishop, Irwin, \& Comber, 2017). Additionally, research has shown that low achieving students access capture more frequently and for longer periods (Owston, Lupshenyuk, \& Wideman, 2011b). In line with this, those using surface learning (i.e. rote learning rather than understanding (Biggs, Kember, \& Leung, 2001)), an approach generally associated with lower performance, are thought to use capture more (Brady et al., 2013; Newton \& McCunn, 2015; Vajoczki et al., 2011). However, another study has shown that more self-regulated students, who may be expected to attain higher grades, may also 
access lecture capture more (Guy, Byrne, \& Dobos, 2017). One consideration may be the motivation for accessing capture i.e. to supplement or substitute for attendance. One study has found that passing students are more likely to supplement lecture attendance with recordings (Von Konsky, Ivins, \& Gribble, 2009) whilst substitution is associated with surface learning (Vajoczki et al., 2011), the earlier stages of a degree (Holbrook \& Dupont, 2009), and when material is perceived as easier (Bassili, 2008). Certainly, attendance is associated with better performance (Brocato, 1989; Edwards \& Clinton, 2018; Golding, 2011; Newman-Ford, Fitzgibbon, Lloyd, \& Thomas, 2008) and research suggests that lecture capture has a greater positive impact on performance of low-attendance students in comparison to high-attending students (Hove \& Corcoran, 2008), although this may not be sufficient to compensate for the impact of low attendance on performance (Edwards \& Clinton, 2018).

Attendance, and how lecture capture might negatively affect this, is one of the main discussion points in the debate around the implementation of lecture capture (Owston, Lupshenyuk, \& Wideman, 2011a). Findings on the impact of lecture capture on attendance are mixed (Pursel \& Fang, 2012). Some studies found a small drop (10-15\%) in attendance when lecture capture was made available (Bryans Bongey et al., 2006; Copley, 2007; Deal, 2007; Traphagan et al., 2010) whilst others reported more substantial drops (17-25\%) (Edwards \& Clinton, 2018; Harley et al., 2003). Yet other studies found that the majority of students did not change their attendance pattern, or that they increased their attendance (Owston et al., 2011b). Students who do not change their attendance pattern in response to lecture capture cite several reasons for this, including a need for routine, a desire to interact with peers and lecturer, and a greater ability to focus when attending live (Brady et al., 2013). 
Irrespective of whether lecture capture results in lower attendance, it is important to recognize that the availability of lecture capture is unlikely to be the only factor determining attendance with other academic and employment responsibilities already identified as important (Cooke et al., 2012; Newton et al., 2014). It is also not a new debate; the advent of the VLE supporting provision of lecture notes raised similar concerns (Drouin, 2014) and, indeed, whilst a significant negative relationship has been found between lecture capture viewing and attendance, availability of other course materials, such as lecture slides, has been shown to have a greater negative effect on attendance (Traphagan et al., 2010). Indeed, where students do miss a lecture, up to 67\% never watch the capture (Drouin, 2014; Goldfarb et al., 2008) indicating that whilst some may use it to substitute attendance, not all rely on it in this way.

Research into staff perceptions of lecture capture is scant (Al-Nashash \& Gunn, 2013), but suggests that staff perceive lecture capture more negatively than students (Danielson, Preast, Bender, \& Hassall, 2014; O'Callaghan et al., 2017), although a single-site study showed approximately $75 \%$ of staff used it to record their live lectures (Germany, 2012). Another study found that $60 \%$ of staff who recorded their lectures used the capture to evaluate their own performance, and that $65 \%$ of staff using capture felt that it had a positive impact on the effectiveness of their teaching (Voort, 2013). The effectiveness could have been improved by altered pedagogy; $18 \%$ stated that they made small changes in pedagogy and $24 \%$ stated significant changes following use of lecture capture (Voort, 2013). There were also reports of better quality of communication when they know lecture capture is used, and although this was not thought to impact on student interaction, it may improve teaching effectiveness (Voort, 2013). Despite this relatively high usage and some positive reflections, staff tend to 
cite extrinsic motives for using capture, notably pressure from students and their university (O'Callaghan et al., 2017). This may explain negative views; people who are motivated to act primarily by external demands tend to derive less satisfaction from such actions than those who are intrinsically motivated (Ryan \& Deci, 2000). Staff are also less convinced of an impact on student performance (Chang, 2007).

In summary, despite research into the perception and impact of lecture capture spanning over a decade, there are still mixed findings and unanswered questions. Furthermore, there is limited research allowing direct comparison of staff and student views of lectures and their capture. In order to begin to address this gap in research literature, we set out to answer the following research questions: i) How do students and staff perceive lecture capture in the context of lectures? ii) How is lecture capture used by students? iii) Are students and staff satisfied with the recordings and aware of the functionality of the lecture capture platform? iv) What factors, if any, predict student perception and use of lecture capture?

\section{Methods and materials}

\subsection{Research Setting and Participants}

This research took place at a large U.K. university, with nine faculties/schools, which offers undergraduate and taught postgraduate programmes utilising lecture capture. At present there are approximately 24,000 undergraduate students and 6000 taught postgraduate students who would typically have access to teaching with lecture capture on at least a proportion of their modules. The university has 3925 members of academic and teaching staff, many of whom will be involved in lecturing regularly. 
Ethical approval was obtained in advance (MR/16/17-1286). Individuals were eligible to participate if they had experience of using lecture capture at the institution and were a i) student studying an undergraduate or taught postgraduate qualification or ii) staff member regularly lecturing on such qualifications. Separate surveys were used for staff and students but in both cases, participants had to confirm that they understood this eligibility before giving consent to participate in the study. Both surveys were advertised via the institutional research recruitment website (internal only) and associated email circular, sent fortnightly to all university staff and students. Additionally, surveys were advertised on the landing page of the VLE. In both cases, the advert contained a brief summary of the study and a link to the full study information and consent form. After accessing the relevant link and providing consent, participants were able to access the survey questions. Nine-hundred and ninety-five people (841 students, 154 staff) accessed the study information and consent form. Of these, 712 (85\%) students and $119(77 \%)$ of staff, gave consent and progressed to the actual survey questions. The final sample consisted of 522 students ( $73 \%$ of those starting the survey questions) and 95 staff members ( $80 \%$ of those starting). The average time taken to complete the survey was 17.6 minutes for staff and 21.9 minutes for students.

\subsection{Measurements}

Data were collected using anonymous online surveys (Qualtrics, UK). Whilst distinct surveys were used for staff and students comparable constructs were measured in both groups. The survey contained self-report measures constructed by the researchers following an extensive literature review and previous qualitative research by the authors (reference to be provided). In most cases responses were on a Likert Scale consisting of either 5 or 7 points, with greater responses options used where previous research indicated greater granularity is needed. The 
surveys were divided into several sections, described briefly below (for full questions and response options see Supplementary Table 1 and 2).

\subsubsection{Participant Characteristics}

The aim of this section was to characterise the sample to allow assessment of representativeness relative to the university population and examine any impact of personal characteristics on measures relating to lecture capture. All participants were asked to indicate gender and their language status (i.e. whether English was their first or second language). Students were also asked if they had any disabilities and staff were additionally asked to indicate their current position at the university. All participants were asked to indicate faculty (school of study), level of qualification they studied or taught at, and types of learning events (LEs) they normally have or teach. This last question allowed us to confirm that both cohorts experienced lectures. Students indicated their weekly contact hours and academic performance level. Academic performance was reported on a categorical scale where higher percentage categories corresponded to higher performance.

\subsubsection{Perception of lectures and lecture capture}

The aim of this section was twofold; firstly, to understand how students and staff view lectures per se and irrespective of capture and, secondly, to gauge perceptions of lecture capture. This twofold approach is important because views of lectures are likely to impact on views of lecture capture.

Usefulness of lectures: All participants rated the usefulness of the different learning events (LEs); for students this was by ranking LEs, and for staff, this item used a Likert scale. Participants then rated the extent to which they felt lectures were effective in supporting the 
achievement of each of four different learning outcomes (LOs; knowledge and understanding, cognitive skills, key skills, professional and practical skills).

Experiencing live lectures: Participants then rated requirements for active participation in lectures by rating their agreement with the statement "Active participation by students in the lecture determines what they can learn from it" for staff and "My active participation and interaction in the lecture determines what I, and others, can learn from it" for students . In the student survey, this was followed by questions about i) the pace of a typical live lecture ii) the volume of material iii) the ease with which notes can be made to support learning in a live lecture. Staff were asked to indicate their level of comfort in delivering lectures (in the absence of any capture) and details of what additional resources they provide to support learning from lectures.

Perception of lecture capture: Overall perception was assessed with a single question in both staff and students, in which they rated their perception of lecture capture. This was followed by agreement ratings for statements about three specific functions of lecture capture: i) making more detailed notes ii) self-pacing of learning iii) more independence in studying. Participants also rated their beliefs about the impact of lecture capture, by rating agreement with statements regarding whether lecture capture impacted on i) the likelihood of the students asking questions in the live lecture ii) teaching style and iii) the material delivered. Finally, staff were asked to rate their comfort on delivering a captured lecture.

\subsubsection{Using lecture capture}

This survey section examined how students use lecture capture and what factors influenced this. 
Frequency and types of use: Students indicated their overall frequency of lecture capture use in a typical week as well as during the period in which they prepared for assessment (coursework or exam). This was followed by ratings for how frequently they used lecture capture to review attended lectures to i) make notes ii) revisit difficult sections iii) help prepare for assessment and to review lectures they had not attended to i) make notes and ii) prepare assessment.

Attendance: We dedicated several questions to attendance, given the emphasis on this topic in previous research. Firstly, students indicated their lecture attendance and we asked staff to estimate attendance in their own sessions, in a typical week. Staff did this for both captured and non-capture lectures. Students were not required to discriminate because some forms of capture may not be obvious to the students (e.g. if it is audio only capture with no visible recording equipment). Staff and students then indicated the perceived importance of the following factors in a student's decision to attend a live lecture: i) cost of travelling to the lecture ii) time taken to travel relative to teaching time iii) early or late scheduling of lecture iv) other academic commitments e.g. coursework deadline v) other academic-related commitments e.g. preparation for interviews/placements vi) family commitments vii) employment commitments viii) availability of online resources such as slides to support learning for the lecture ix) availability of lecture capture for the lecture. Finally, students were asked to indicate when they were most likely to watch an available lecture capture if they have missed a live lecture. 


\subsubsection{Satisfaction and technical awareness}

This final survey section aimed to establish satisfaction with the recordings made and technical knowledge of lecture capture because it seems logical that these would impact on use of lecture capture.

Satisfaction: All participants rated their satisfaction with i) audio quality ii) video quality (if applicable) iii) delay between live event and availability and iv) ease of access.

Technical awareness: Participants indicated their awareness of i) variable playback speed ii) pause/restart facility iii) bookmarking iv) creation and download study notes v) mobile app usage, and how useful they thought these functions were.

\section{Results}

\subsection{Participant characteristics}

The final sample is summarised in Table 1.

Table 1 Sample characteristics.

Sample Characteristics

Gender

Male

Female

Prefer not to say

English First Language

Yes

No

Prefer not to say

Qualification

Undergraduate

Postgraduate

Faculty representation (out of 9)

Disability

Yes
Students $(N=522)$

Staff $(N=95)$

165 60

349

27

8

8

382

68

140

27

0

0

410

64

111 29

9

8 
Prefer not to say

Academic performance $(\% /$ mode)

60-69

Average (mode) Contact hours (hrs)

$9-16$

The student sample was comparable to the available data for our institution from the Higher Education Statistics Agency (HESA), who collect data on students from U.K. universities. Specifically, HESA data indicates that there are almost twice as many female (63\%) to male students (37\%), in line with our sample consisting of $67 \%$ identifying as female. Additionally, whilst HESA do not specifically collect data on English Language Status, data indicates that $65 \%$ of students are from within the UK, and obviously many international students will still have English as a first language which broadly corresponds to the $26 \%$ of students participating in the study who did not have English as a first language. University data indicates approximately $11 \%$ of our students have a recorded disability, again in line with the current sample ( $9 \%$ of those giving an answer). Finally, the proportion of undergraduate $(79 \%)$ and postgraduate $(21 \%)$ students in the sample is comparable to that in the university as a whole $(75 \%$ UG) indicating a representative sample. The student sample also included representation from all faculties or schools of the university. The staff sample included representatives from most faculties. However, the proportion of males completing the survey (69\% identifying a gender) is slightly higher than might be expected given that males constitute only $52 \%$ of the academic and teaching staff at the institute. In terms of position held, whilst there was a range of positions reported, the balance between them was not representative of the overall staff population: professors $26.9 \%$ of survey sample $(17.7 \%$ university staff); reader $9.6 \%$ (6.6\%); senior lecturer $16.1 \%$ (12.8\%); lecturers $26.9 \%$ (12.7\%) and teaching fellows $12.9 \%$ (47.5\%), with teaching fellows under represented. 
All participants confirmed that they had experience of using lecture capture and $99 \%$ of students and staff reported currently having or giving lectures. Furthermore, most had experience with more than one type of LE (Students $90.9 \%$, Staff $77.9 \%$ ) with the majority currently experiencing all three types (Students $51.6 \%$, Staff $48.9 \%$ ), indicating that the respondents had sufficient experience of lectures and other types of $L E$ to provide meaningful answers.

\subsection{Student and staff perception of lectures and lecture capture}

Usefulness of lectures: Most students (43.7\%) ranked lectures as bringing the greatest value to their learning experience, followed by seminars or tutorials (32.0\%) and then practicals or workshops (24.3\%). Chi-square test showed that there was no significant association between the most highly valued learning event and gender (men, women), $\chi^{2}(2)=1.76, p=0.414$, disability (yes, no), $\chi^{2}(2)=4.10, p=0.129$, English language status (first language, second language), $\chi^{2}(2)=2.90, p=0.235$, or qualification (undergraduate, postgraduate), $\chi^{2}(2)=4.48$, $p=0.106$, indicating lectures are highly valued by all students regardless of these personal characteristics. Staff ratings on the utility of the different learning events were analysed with a repeated-measures ANOVA, and showed a significant difference between the events, $F(1.82,140.49)=5.78, p=0.005$. Post-hoc paired-sample t-tests (corrected $\alpha=0.025)$ revealed that lectures $(M=4.38, S E=0.07)$ were viewed as significantly less useful than seminars or tutorials $(M=4.63, S E=0.07), t(90)=3.26, p=0.002$ and practicals or workshops $(M=4.66$, $S D=0.08), t(78)=2.80, p=0.006$. This indicates that, unlike students, staff felt lectures had the least value to learning. However, as with students, the usefulness ratings of different learning events did not differ according to 
gender (lectures, $t(85)=0.43, p=0.671$; seminars or tutorials, $t(82)=0.79, p=0.432$; practicals or workshops, $t(71)=0.30, p=0.765$ ) or English language status (lectures, $t(93)=0.87, p=0.392$; seminars or tutorials, $t(89)=1.67, p=0.098$; practicals and workshops, $t(77)=1.15, p=0.254)$. Interestingly, whilst staff saw the utility of lectures and practicals or workshops as comparable for undergraduate and postgraduate students (lectures, $t(91)=-0.63, p=0.529$, or practicals and workshops, $t(75)=1.43, p=0.158)$, they reported seminars and tutorials as significantly more useful for undergraduates $(M=4.74, S E=0.06)$ than for postgraduates $(M=4.43, S E=0.18)$, $t(87)=2.09, p=0.04$.

Staff and students also rated the usefulness of lectures in supporting distinct categories of learning outcomes. A mixed-ANOVA with group (staff vs. student) as the between-subjects factor and learning outcome as the within-subjects factor showed a significant main effect of learning outcome category, $F(3,1827)=210.335, p<0.001$ but no significant effect of group, $F(1,609)=1.187, p=0.276$, or interaction effect $F(3,1827)=2.193, p=0.087$. Post-hoc pairedsample t-tests (corrected $\alpha=0.0083$ ) revealed that significant differences between all learning outcomes $(p<0.001)$ with lectures best supporting knowledge and understanding $(M=3.98$, $S E=0.04)$, followed by cognitive skills $(M=3.14, S E=0.05)$, key skills $(M=2.99, S E=0.05)$ and finally professional and practice skills $(M=2.63, S E=0.05)$.

Experiencing live lectures: We next analyzed the rating that staff and students gave to the need for active participation by learners during lectures using an independent-sample t-test. This revealed a significant difference between the groups, $t(613)=5.261, p<0.001$ with staff having higher participation requirements $(M=5.45, S E=0.15)$ than students $(M=4.44, S E=0.08)$. In terms of the lecture experience, a minority of students felt that lectures were far too slow $(1.5 \%)$ or far too fast $(5.0 \%)$, whilst most felt the pacing was either appropriate $(41.5 \%)$ or 
slightly too fast (39.5\%). A similar pattern was found for volume of material with a small proportion believing far too little $(0.8 \%)$ or far too much $(10.9 \%)$ was included and most falling into the categories of appropriate amount (43.2\%) or slightly too much material $(37.4 \%)$. Unsurprisingly, answers to these two questions were significantly correlated indicating that, for example, those who felt lecture pace was too slow also felt the volume of material was too low $(r=0.369, p<0.001)$. Despite most students feeling that the pace and volume was appropriate, more students reported finding it difficult to make notes to some degree $(58 \%)$ than finding it easy $(27 \%)$ with the remainder (14\%) finding it neither easy or difficult. The most commonly reported level of difficulty was 'Slightly difficult' (34.5\%). This indicates that a significant proportion of students find note-taking challenging to some degree. There were significant correlations between difficulty of note-taking and pace and volume such that as pace or volume increased it became harder to take notes in the live lecture (Pace $\sim$ Notetaking ease, $r=0.325, p<0.001$; Volume $\sim$ Note-taking ease, $r=0.313, p<0.001)$. Staff rated their comfort with delivering lectures in the absence of any capture with $76.8 \%$ reporting that they were extremely comfortable doing so. There were no significant differences in comfort of delivering uncaptured lectures between men and women $(t(85)=1.36, p=0.178)$, those with and without English as a first language $(t(93)=-0.57, p=0.571)$ and those teaching at undergraduate and postgraduate level $(t(91)=-0.42, p=0.678)$.

Finally, to better understand the range of materials that students have to support their learning from lectures, staff were asked to confirm which of the following they provided; the percentage providing these is shown in brackets: Copies of slides (78.9\%); Lecture Notes (45.3\%); Interactive activities e.g. quizzes (24.2\%); Related forum discussions (22.1\%); 
Reading lists (69.5\%). Of the 95 staff surveyed, 3.2\% reported not giving any of the above resources.

Perception of lecture capture: Most students held very positive (44.4\%) or somewhat positive (39.1\%) views of lecture capture. Only 9.6\% held negative views and 6.9\% had neither positive nor negative views. Staff perceptions were less positive with only $7.4 \%$ seeing it as very positive and a further $42.1 \%$ seeing it as somewhat positive. Moreover, in contrast to less than $10 \%$ of students seeing it as very negative, $33.7 \%$ of staff viewed it this way. There were also more who were undecided with $16.8 \%$ viewing it as neither positive nor negative. $\mathrm{A}$ comparison of staff and students revealed that students viewed lecture capture as significantly more positive than staff, $t(615)=10.74, p<0.001$. The ratings for both groups did not different significantly according to gender (students $t(512)=0.43, p=0.667$, staff $t(85)=1.82, p=0.720)$, qualification (students $t(519)=0.06, p=0.953$, staff $t(91)=1.17, p=0.246$ ) or English Language Status (students $t(520)=0.168, p=0.867$, staff $t(93)=1.13 ; p=0.260$ ). For students, there was also no significant difference in perception of lecture capture by contact hours, $F(4,517)=1.73, p=0.142$, or performance, $F(4,427)=1.50, p=0.201)$. However, there was a significant difference between those with and without disability, $t(505)=1.971, p=0.049$; those with a disability viewed lecture capture more favourably $(M=4.43, S E=0.12)$ than those without $(M=4.14, S E=0.05)$.

Figure 1 shows the ratings for whether they believed lecture capture enable three specific learning elements of learning. There was no significant difference between staff and student ratings about allowing self-pacing, $t(615)=1.79, p=0.253$, or independent study, $t(615)=1.91$, $p=0.217$, but students had significantly stronger agreement with the statement that lecture capture enabled them to make more detailed notes, $t(615)=5.226, p=0.001$. 


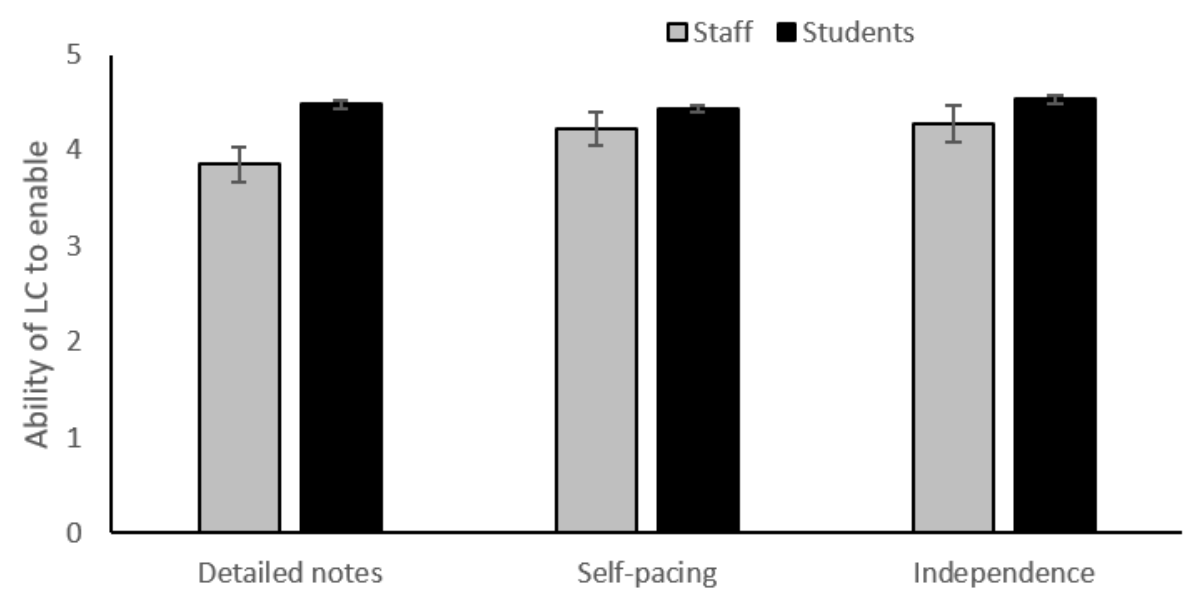

Element of learning

Figure 1: Student and staff ratings on the ability of lecture capture to support detailed note-taking, self-pacing and independent learning.

Ratings regarding the impact of lecture capture on the live lecture are shown in Figure 2. For all measures staff felt the impact was significantly greater than students (reducing questions, $t(614)=5.37, p<0.001$, teaching style, $t(614)=5.03, p<0.001 ;$ material, $t(614)=6.73, p<0.001)$.

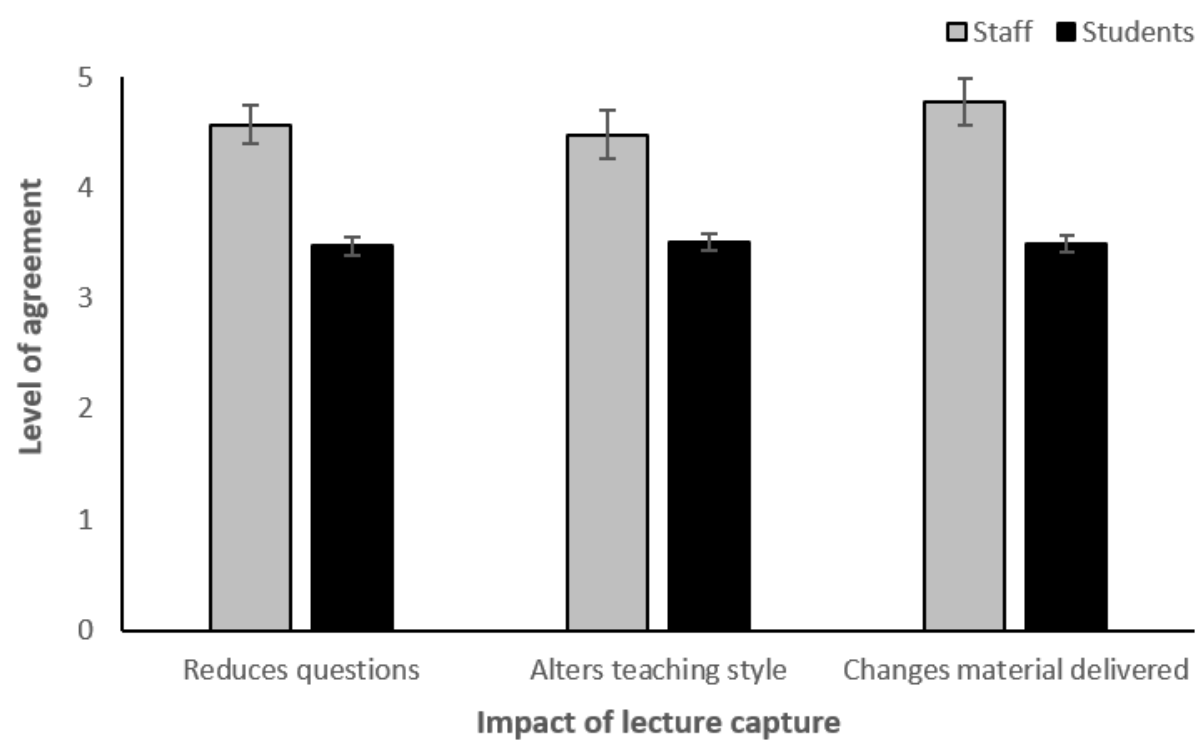

Figure 2 Strength of agreement (mean \pm SE) between staff and student about the possible impact of lecture capture on different aspects of the live lecture. 
Staff comfort ratings were directly compared for delivering captured and non-captured lectures using a paired-samples t-test, revealing that staff were significantly less comfortable delivering captured lectures, $t(94)=8.63, p<0.001$.

\subsection{Using Lecture Capture}

Frequency and types of use: The most commonly reported frequency of lecture capture use by students was once a week during a typical term week (39.8\%) and 2-3 times week during assessment periods (27.8\%). Frequency of lecture capture use during term and assessment periods significantly correlated, $r=0.417, p<0.001$, although average use was significantly higher during assessment preparation $(M=3.58, S E=0.06)$ than during term $(M=2.87, S E=0.05)$, $t(521)=12.37, p<0.001$. This suggests that the students increase their frequency of use slightly during assessment rather than completely altering their pattern or initiating high use when they had previously not used it. There was no difference in frequency of use lecture capture across genders for a typical term week, $t(512)=0.89, p=0.374$, or during assessment preparation, $t(512)=0.89, p=0.654$. Also comparing those with English as first and second language did not significantly differ on these frequency ratings, $t(520)=1.06, p=0.291$, and, $t(520)=1.35, p=0.177$, respectively. There was also no difference between those with a declared disability and those without, $t(505)=0.52, p=0.607$, and, $t(505)=0.35, p=0.727$, respectively. However, there was a difference between postgraduates and undergraduates, with the latter using lecture capture more frequently during a typical term week $(M=3.02$, $S E=0.06$ vs $M=2.34, S E=0.08), t(519)=5.64, p<0.001$, and during assessment preparation $(M=3.64, S E=0.06$ vs $M=3.36, S E=0.12), t(519)=2.09, p=0.038$. Rank order correlation analysis revealed that there was a significant negative correlation between estimated performance and use of lecture capture during term time, $r_{s}=-0.106, p=0.027$, and during assessment 
preparation, $r_{s}=-0.125, p=0.009$. This suggests that in both periods higher performing students use lecture capture at a lower frequency. Rank order correlation analysis also revealed that there was a significant correlation between contact hours and use of lecture capture during term time, $r_{s}=0.237, p<0.001$, but not during assessment preparation, $r_{s}=0.075, p=0.089$. Students with more contact hours during term time use lecture capture more frequently.

Figure 3 shows the frequency of use of lecture capture for different purposes when a lecture has been attended or missed. For students who attended the lecture the most frequent reason for using lecture capture was to support assessment, followed by reviewing difficult sections and note-taking. Despite note-taking being ranked lowest it should be acknowledged that around one quarter of students attending a lecture reported always using the capture to take notes. Of those not attending the most frequent use was to take notes.

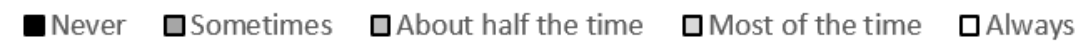

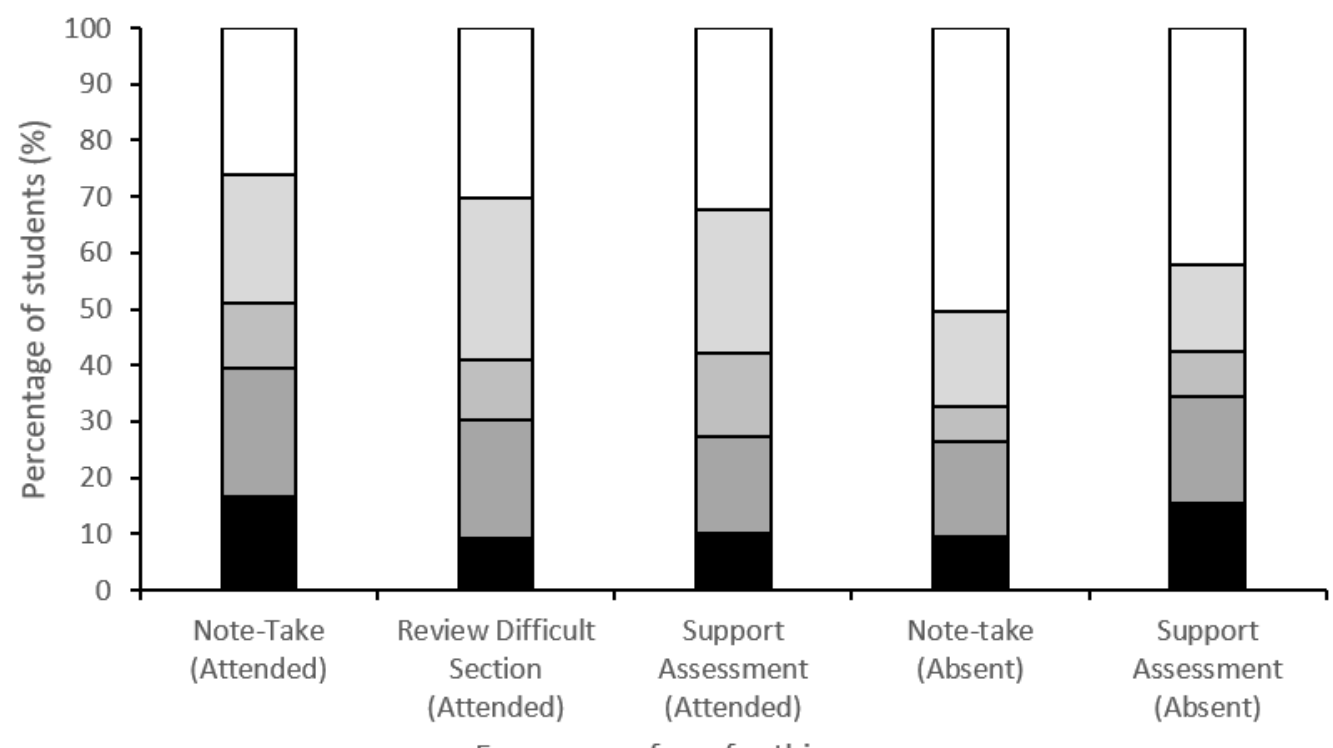

Frequency of use for this purpose

Figure 3 Use of lecture capture for different purposes in students who attend lect ures and those who miss them. 
It is noteworthy that there were significant correlations between all post-attendance measures (Note-taking Reviewing difficult sections, $r=0.723, p<0.001$; Note-taking $\sim$ Support assessment, $r=0.545, p<0.001$; Reviewing difficult sections $\sim$ Support assessment, $r=0.588$, $p<0.001)$. There was also a significant correlation between the different uses for those not attending (Note-taking Supporting Assessment, $r=0.716, p<0.001$ ). However, there were also some weak but significant correlations between measures for post attendance and having missed lectures. For example, there was a positive correlation between using lecture capture to make notes both after attending and when a lecture was missed $r=0.113, p<0.05$, and for using it for assessment in both contexts $r=0.235, p<0.001$. This indicates that students tended to adopt similar approaches to using lecture capture, irrespective of whether they attended.

Attendance: The largest single group of students (46\%) reported attending all lectures, whilst a minority reported attending none (3.8\%). Notably, most stated that they would try to catch up as soon as possible and before the next lecture if they did miss a session (53.7\%), whilst $34.2 \%$ said they would catch up during term but this would not necessarily be before the next lecture and $10.7 \%$ said they would catch up during revision. This leaves only $1.3 \%$ who said they will never catch up. To establish which factors related to attendance from a student perspective (e.g., scheduling, employment, online resources), responses on the nine questions regarding this were used in an oblimin-rotated exploratory factor analysis, which revealed three factors with eigenvalues above $\lambda=1$ : difficulty of attendance $(\lambda=3.872$; cost, time, \& scheduling), other commitments ( $\lambda=1.217$; other academic, academic related, family, employment), and online resources ( $\lambda=1.018$; online lecture resources, availability of lecture capture). Computed averages for these three factors were used in a linear regression to predict attendance. Regression analysis revealed that these predictors accounted for a 
significant amount of variance in attendance, $F(3,515)=25.58, p<0.001, R^{2}=13.0 \%$. Table 2 shows that difficulty of attendance and online resources were significant negative predictors of attendance.

Table 2 Linear model of predictors of student attendance at lectures based on student ratings of attendance and importance of factors.

\begin{tabular}{l|cccc}
\multicolumn{1}{l}{ CONSTANT } & $\boldsymbol{B}(\mathbf{9 5 \%} \mathrm{Cl})$ & $\boldsymbol{S E}$ & $\boldsymbol{B E T A}$ & $\boldsymbol{P}$ \\
& 0.003 & 0.041 & & 0.933 \\
DIFFICULTY OF ATTENDANCE & $(-0.077,0.084)$ & & & \\
& -0.141 & 0.049 & -0.142 & 0.004 \\
OTHER COMMITMENTS & $(-0.239,-0.044)$ & & & \\
& 0.040 & 0.048 & 0.040 & 0.407 \\
ONLINE RESOURCES & $(-0.055,0.135)$ & & & \\
& -0.291 & 0.047 & -0.292 & $<0.001$
\end{tabular}

Staff estimates of attendance showed that the single largest group (40.4\%) were thought to be those who attend around half of their lectures when they were captured. By contrast, staff believed the single largest group to be the $51.5 \%$ who attend around three quarters of the available lectures when no capture was used. Staff ratings of attendance were significantly different between the two types of lecture, $t(69)=7.47, p<0.001$, with the estimated attendance much higher for non-captured lectures. An oblimin-rotated exploratory factor analysis, examining the possible factors that could impact on attendance revealed three factors with eigenvalues above $\lambda=1$ : Difficulty of attendance $(\lambda=4.249 ;$ travel cost, time and scheduling, employment commitments), resources $(\lambda=1.329$; online lecture resources, availability of lecture capture) and other commitments ( $\lambda=1.254$; other academic, academic related and family commitments). These three factors were used in a linear regression to predict attendance at captured lectures. Regression analysis revealed that these predictors accounted for a significant amount of variance in attendance, $F(3,82)=3.921, p=0.011$, 
$R^{2}=12.5 \%$. Table 3 shows that the only significant predictor variable was the availability of online resources which negatively affected attendance. No variables predicted attendance at non-captured lectures, $F(3,71)=0.430, p=0.732, R^{2}=0.02 \%$.

Table 3 Linear model of predictors of student attendance based on staff ratings of attendance and the importance of factors on attendance.

\begin{tabular}{l|cccc} 
& $\boldsymbol{B}(\mathbf{9 5} \% \mathbf{C l})$ & $\boldsymbol{S E}$ & $\boldsymbol{B E T A}$ & $\boldsymbol{P}$ \\
\hline CONSTANT & 4.048 & 0.473 & & $<0.001$ \\
DIFFICULTY OF ATTENDANCE & $(3.11,4.99)$ & & & \\
& 0.001 & 0.127 & 0.001 & 0.992 \\
OTHER COMMITMENTS & $(-0.25,0.25)$ & & & \\
& 0.022 & 0.125 & 0.021 & 0.860 \\
ONLINE RESOURCES & $(-0.23,0.27)$ & & & \\
& -0.315 & 0.095 & -0.357 & 0.001
\end{tabular}

\subsection{Satisfaction and technical Features}

Ratings of satisfaction with the four features of lecture capture recordings (Table 4) were analysed with a mixed-ANOVA with feature as the within-measures factor and group as the between-measures factor. There was a significant main effect of both feature, $F(2.71$, $1449.85)=20.63, p<0.001$, and group, $F(1,536)=11.33, p=0.001$. Staff were significantly less satisfied than students. Furthermore, post-hoc paired-sample t-tests (corrected $\alpha=0.008$ ) revealed that all features differed significantly from each other $(p<0.001)$ with audio being the feature that users were least satisfied with, followed by video, delay and then ease of access. There was also a significant interaction, $F(2.71,1449.85)=4.04, p=0.011$. Post hoc independent-sample t-test indicate this arises because staff and students differed significantly (corrected $\alpha=0.0125$ ) for all features except the delay where there was no significant difference $(p=0.337)$.

Table 4 Staff and student satisfaction ratings (mean $\pm \mathrm{SE}$ ) for the different features of the recordings produced from lecture capture. 


\begin{tabular}{l|llll}
\multicolumn{1}{c}{} & Audio Quality & Video Quality & Delay & Ease of Access \\
\hline Staff & $2.99 \pm 0.14$ & $2.87 \pm 0.15$ & $3.51 \pm 0.13$ & $3.67 \pm 0.13$ \\
Students & $3.38 \pm 0.05$ & $3.64 \pm 0.05$ & $3.64 \pm 0.051$ & $4.13 \pm 0.05$
\end{tabular}

As well as differences in satisfaction, there were also differences in awareness of specific functions and their perceived usefulness (Table 5). Usefulness ratings were analysed using a mixed-ANOVA with feature as the within-measures factor and group as the betweenmeasures factor. There was a significant main effect of function, $F(2.88,1404.14)=59.28$, $p<0.001$. Post-hoc paired-sample t-tests (corrected $\alpha=0.005$ ) show highly significant differences between each of the features $(p<0.001)$, except for bookmarking $(p=0.07)$ and ability to view through the mobile app $(p=0.02)$. The feature rated as most useful was the ability to pause and restart, followed by the ability to adjust the speed, bookmark, using the mobile app and creating study notes. There was a significant main effect of group, $F(1$, $487)=54.87, p<0.001$, with students providing higher ratings than staff. There was also a significant interaction, $F(2.88,1404.14)=18.68, p<0.001$. Post-hoc independent-sample t-test indicate this arises because staff and students differed significantly (corrected $\alpha=0.01$ ) for all features except the bookmarking where there was no significant difference $(p=0.023)$.

Table 5 Staff and student awareness (\%) of specific features followed by usefulness ratings expressed as mean $\pm \mathrm{SE}$.

Speed Pause/restart Bookmarking Study notes Mobile app

\begin{tabular}{l|ccccc}
\hline Staff & 34.7 & 66.3 & 14.7 & 11.6 & 9.5 \\
& $(2.87 \pm 0.15)$ & $(3.51 \pm 0.16)$ & $(3.09 \pm 0.15)$ & $(2.75 \pm 0.15)$ & $(2.83 \pm 0.16)$ \\
Students & 76.8 & 92.7 & 23.9 & 28.2 & 26.2 \\
& $(4.39 \pm 0.05)$ & $(4.72 \pm 0.03)$ & $(3.46 \pm 0.07)$ & $(3.22 \pm 0.07)$ & $(3.40 \pm 0.07)$
\end{tabular}




\subsection{Predicting perception and frequency of use}

Based on the above analyses, several variables were considered as potential predictors of both student perception of lecture capture (i.e. how positively or negatively it was viewed) and frequency of use. These variables were used in an oblimin-rotated exploratory factor analysis, which revealed six factors with eigenvalues above $\lambda=1$ : Learning support $(\lambda=3.08$; lecture capture supports detailed note-taking, self-pacing, and independent study), Impact on live event ( $\lambda=2.147$; impact on questioning, teaching style, or content), Substitution use ( $\lambda=1.894$; use to make notes or support attendance if not attended), Satisfaction $(\lambda=1.658$; satisfaction with video quality, delay, and ease of access), post-attendance use ( $\lambda=1.518$; use to make notes, review difficult sections, or support assessment) and Lecture load ( $\lambda=1.215$; pace, volume, and ease of note taking in live event). These six factors, along with attendance, awareness of function within lecture capture, and disability status were used in a linear regression to predict perception of lecture capture. Regression analysis revealed that these predictors did not significantly predict perception of lecture capture, $F(9,493)=0.904$, $p=0.521, R^{2}=0.013$.

A similar analysis was conducted for frequency of use (as an average of use during typical weeks and during assessment preparation, given their correlation). This revealed five factors with eigenvalues above $\lambda=1$ : Learning support $(\lambda=2.44$; lecture capture supports detailed note-taking, self-pacing and independent study), Lecture load ( $\lambda=1.99 ;$ pace, volume and ease of note taking in live event), Impact on live event $(\lambda=1.80$; impact on questioning, teaching style or content), Access Satisfaction ( $\lambda=1.22$; satisfaction with ease of access and delay before release). Recording Quality ( $\lambda=1.02$; satisfaction with audio quality and video quality), These five factors along with awareness of features, qualification (postgraduate vs undergraduate), 
performance and contact hours were used in a linear regression to predict frequency of use. Regression analysis revealed that these predictors collectively explained a significant amount of variance in frequency of use $F(10,418)=13.15, p<0.001, R^{2}=0.239$. Table 6 shows that there were several significant positive predictors of frequency of use i) lecture load such that the higher the perceived demand of the live lecture, the greater the use of capture ii) awareness of features such that those more aware of the features of the lecture capture software were more likely to use it iii) contact hours with those with a greater number of hours more likely to use lecture capture. There were also several negative predictors i) those who perceived lecture capture more able to support learning through making detailed notes, self-pacing and independence were less likely to use it ii) performance such that lower performing students were more likely to use it iii) attendance with the students with lower attendance more likely to use it.

Table 6 Linear model of predictors of frequency of use.

\begin{tabular}{|c|c|c|c|c|}
\hline & $B(95 \% C l)$ & $S E$ & BETA & $\boldsymbol{P}$ \\
\hline CONSTANT & $\begin{array}{c}0.338 \\
(-0.156,0.832)\end{array}$ & 0.251 & & 0.179 \\
\hline LEARNING SUPPORT & $\begin{array}{c}-0.182 \\
(-0.279,0.085)\end{array}$ & 0.049 & -0.169 & $<0.001$ \\
\hline LECTURE LOAD & $\begin{array}{c}0.183 \\
(-0.092,0.275)\end{array}$ & 0.046 & 0.184 & $<0.001$ \\
\hline IMPACT ON LIVE EVENT & $\begin{array}{c}0.023 \\
(-0.065,0.110)\end{array}$ & 0.044 & 0.023 & 0.610 \\
\hline ACCESS SATISFACTION & $\begin{array}{c}0.00 \\
(-0.089,0.088)\end{array}$ & 0.045 & 0.000 & 0.993 \\
\hline RECORDING SATISFACTION & $\begin{array}{c}0.069 \\
(-0.021,0.159)\end{array}$ & 0.046 & 0.070 & 0.132 \\
\hline AWARENESS OF FEATURE & $\begin{array}{c}0.226 \\
(0.138,0.313)\end{array}$ & 0.044 & 0.225 & $<0.001$ \\
\hline LEVEL OF STUDY & $\begin{array}{c}-0.151 \\
(-0.389,0.087)\end{array}$ & 0.121 & -0.056 & 0.212 \\
\hline PERFORMANCE & $\begin{array}{c}-0.141 \\
(-0.251,-0.030)\end{array}$ & 0.056 & -0.113 & 0.013 \\
\hline CONTACT HOURS & 0.120 & 0.037 & 0.142 & 0.001 \\
\hline
\end{tabular}




\section{ATTENDANCE}

$(0.047,0.194)$

$$
-0.153
$$

0.045

$-0.156$

0.001

$(-0.242,-0.065)$

\section{Discussion}

This study had several research questions, and each will be considered in turn beginning with the findings about how staff and students perceive lectures and lecture capture. Responses from students indicated that lectures were highly valued, in line with previous research (Covill, 2011) and that this value was stable across student characteristics. Staff were less positive about the value of lectures. This is perhaps unsurprising given the relatively recent stigmatization of lectures and debates about their suitability (DiPiro, 2009; Gross-Loh, 2016). Despite the different value attributed to lectures, staff and students held similar beliefs about how effectively the lecture supported development of LOs with those centred around knowledge and understanding more effectively supported by lectures, in line with previous research (Kirkpatrick, 1990). However, cognitive and key skills were less well supported which is perhaps surprising based on previous research around modelling behaviour and note-taking which would fall into these categories (Feldon, 2010; Titsworth, 2001). Staff also felt that students must be more active in their participation in lectures than students did. This difference may stem from the emphasis on active learning (Chickering \& Gamson, 1987), which students may be less aware of that staff. In summary, the data from the present study indicate that both staff and students see lectures as an opportunity to develop knowledge but, whilst students place a higher value on this experience than staff, they also believe it requires less participation.

Perhaps unsurprisingly given the difference in perceived value of lectures, and in line with the previous research, students viewed lecture capture positively (Gosper et al., 2008; Heilesen, 
2010; McGarr, 2009; O'Callaghan et al., 2017; Pons et al., 2012; Traphagan et al., 2010) and significantly more so than staff (Danielson et al., 2014; O'Callaghan et al., 2017), who found delivering captured lectures less comfortable than non-captured. The current results suggest that the popularity of lecture capture is stable across most student characteristics as has been previously found. It differed only for students with disabilities who perceived it more favourably than those without. We did not ask students to indicate the nature of their disability, but it is likely that the more positive perception arises because lecture capture helps overcome difficulties caused by their disability, as has been found previously (Newton et al., 2014). Also in line with previous research, students felt lecture capture supported self-pacing, independent study and detailed note-taking (Al-Nashash \& Gunn, 2013; Elliott \& Neal, 2016; Gosper et al., 2010; Newton et al., 2014; Saunders \& Hutt, 2015; Watt et al., 2014). Staff also recognised that these were enabled by lecture capture to a similar degree for self-pacing and independent study but were less convinced that lecture capture supported detailed notetaking, even though a significant body of research now shows this. The perceived impact of lecture capture was considered in terms of material, teaching style and participation by both staff and students. In all cases, staff perceived the impact to be greater than students. For the material covered and teaching style, this could be explained by the fact that students are only privy to the final lecture and so are unaware of what a staff member may have delivered in the absence of capture. The final measure of participation may be explained by the differences in expected level of participation between staff and students, with staff expecting higher participation from students. The staff findings are partially at odds with previous research which did report impact on teaching style but not on participation (Voort, 2013).

Considering our second research question, focusing on how students use lecture capture, we found that students use capture during both typical weeks and for assessment, with higher 
use during the latter as has been found previously (Brady et al., 2013; Gosper et al., 2010; Saunders \& Hutt, 2015). However, unlike perception of lecture capture, frequency of use did differ according to several student characteristics. Firstly, we found that undergraduates are more likely to use capture than postgraduates. Secondly, lower-performing students used capture more, as has been shown previously (Brady et al., 2013; Newton \& McCunn, 2015; Owston et al., 2011b; Vajoczki et al., 2011). Finally, we report that students with a greater number of contact hours are more likely to use lecture capture. This is presumably because they find it difficult to attend all their lectures or have difficulty sustaining attention for consecutive lectures. The exact use of lecture capture varied slightly when students were using it to supplement as opposed to substitute attendance. In the former, students were most likely to use it to support assessment, whilst the latter were most likely to use it to make notes. Both suggested uses have been identified previously, although their uses in the different context has not been considered before.

Attendance is a highly contentious issue for lecture capture with some studies showing quite substantive drops in attendance with the availability of lecture capture (Edwards \& Clinton, 2018; Harley et al., 2003). The present study analysed nine possible factors important in determining attendance. The results from the student data revealed that whilst lecture capture does negatively predict attendance along with the availability of other online resources (e.g. copies of slides), it is not just learning resource availability that impacts attendance. We have demonstrated that the difficulty in attending is also a significant predictor from the students' perspective. The impact of other factors has been suggested previously (Cooke et al., 2012; Newton et al., 2014) but this is the first study showing a clear relationship between lecture capture, other factors and attendance. Interestingly, staff data did not find any factors predicted attendance at non-captured lectures and did not indicate 
that difficulty in attendance is a key consideration in captured lectures. These results indicate that students are considering a wider range of factors when deciding whether to attend a lecture than staff believe them to consider.

Our third research question examined how satisfied staff and students were with the recording and how aware they were of the different functions of the platform. Students were found to be more satisfied in general than staff, something which may have contributed to the more positive overall perception in students. Students were considerably more aware of the functions than staff, which is unsurprising given they are the main users of the recordings. This was particularly pronounced for speed adjustment and study notes, which may explain why staff were less convinced by lecture capture enabling note-taking.

Our final research question was to examine what factors, if any, predicted perception and frequency of use in students. We did not find any factors that predicted perception, this is likely because most students perceived lecture capture as positive meaning we did not have the variance for meaningful analysis here. By contrast we found several factors to predict frequency of use. Firstly, there are factors that can be coined Learner Demand Factors incorporating i) load of the live lecture (pace, volume of material and ease of note-taking, and ii) contact hours. For these, the higher the factor e.g. the greater load, the higher the use. Secondly, there are those we have termed Capture Solutions which refer to factors where the learner can perceive a solution or gain through lecture capture. Included in this section are i) functional awareness ii) performance level and iii) attendance level. This category includes positive and negative predictors such that a greater awareness of the functions increases use whilst a higher performance and attendance decrease use. Finally, we found that those who perceived lecture capture more able to support learning through making detailed notes, self- 
pacing and independence were less likely to use it. This appears to be an anomaly because logically we expect that this would be a positive predictor of use. However, it is possible that students who see lecture capture as being capable of doing this, can also identify other methods for achieving this.

There are several limitations of the current study. Firstly, we relied on self-report measures. Previous research suggests that self-report can be reliable provided that the information is known to respondents and that the questions are i) unambiguous ii) relate to recent activity iii) require a serious and thoughtful response, and iv) will not lead to embarrassing or threatening disclosures (Kuh, 2001; Owston et al., 2011b). We believe these conditions were met in the current study and certainly our findings around the most sensitive questions e.g. performance level, are in line with previous research. Secondly, whilst we had a substantial sample of students in line with some of the larger studies in the current literature, the sample who completed the survey represented only around $2 \%$ of the total eligible students in the university. The size of the sample is, arguably less important that representativeness (Cook, Heath, \& Thompson, 2000) and statistical power, but this should be noted. The staff sample was small and did not include all faculties of the university. Furthermore, the balance of positions held by staff in the sample did not reflect the positions in the wider institutions. This may be because only those more involved in lecturing contributed to the sample, but it is not possible to tell this from institutionally available data and therefore we cannot be certain that staff findings may not generalize to the wider population. Finally, as with all research of this kind, there is likely to be some self-selection bias, with those holding the strongest views choosing to participate. However, given that there was a good range of scores across most measures and the student sample is clearly representative of the wider university, any selfselection bias should not negate the findings. 


\section{Conclusions}

We found that students hold positive views of lectures and lecture capture, perceiving lectures as effective in developing knowledge and understanding and requiring little participation. They use capture in a range of ways and have good awareness of platform functionality. They also perceive little impact of lecture capture on lecture content, teaching style and their participation. Generally, those experiencing greater learner demand will use it more frequently. Furthermore, availability of lecture capture does impact negatively on attendance, along with availability of other online resources and general difficulty in attending, meaning that lecture capture alone is not determining attendance. As expected from this, lower attending students use capture more. The same is true of lower performing students. Staff have less favourable views of lectures and lecture capture, and although they consider lectures effective in developing knowledge and understanding, they expect higher student participation. Staff perceived the availability of online resources including capture as the only predictor of attendance and have little awareness of the functions of the lecture capture platform that can support learning. In summary, there are some shared views around lectures and lecture capture between staff and students but there are also substantial differences at a basic level e.g. awareness of software functionality and at a higher level e.g. expectation of active learning. It seems unlikely that these differences will simply disappear and therefore, without active interventions to develop shared understanding and views, lecture capture is likely to remain a contentious issue.

\section{Acknowledgments}

The authors would like to thank James Toner, Lyndsey Welch and Nabila Raji for their helpful comments on the survey. 


\section{Funding sources}

This research did not receive any specific grant from funding agencies in the public, commercial, or not-for-profit sectors. 


\section{References}

Abt, G., \& Barry, T. (2007). The quantitative effect of students using podcasts in a first year undergraduate exercise physiology module. Bioscience Education, 10(1), 1-9.

Al-Nashash, H., \& Gunn, C. (2013). Lecture capture in engineering classes: Bridging gaps and enhancing learning. Educational Technology \& Society, 16(1), 69-78.

Bassili, J. N. (2008). Media richness and social norms in the choice to attend lectures or to watch them online. Journal of Educational Multimedia and Hypermedia, 17(4), 453.

Behr, A. (1988). Exploring the lecture method: An empirical study. Studies in Higher Education, 13(2), 189-200.

Biggs, J., Kember, D., \& Leung, D. Y. (2001). The revised two-factor Study Process Questionnaire: R-SPQ-2F. Br J Educ Psychol, 71(Pt 1), 133-149.

Bollmeier, S. G., Wenger, P. J., \& Forinash, A. B. (2010). Impact of online lecture-capture on student outcomes in a therapeutics course. American journal of pharmaceutical education, 74(7), 127.

Brady, M., Wong, R., \& Newton, G. (2013). Characterization of catch-up behavior: accession of lecture capture videos following student absenteeism. Education Sciences, 3(3), 344-358.

Brecht, H., \& Ogilby, S. (2008). Enabling a comprehensive teaching strategy: Video lectures. Journal of Information Technology Education: Innovations in Practice, 7(1), 71-86.

Brocato, J. (1989). How much does coming to class matter? Some evidence of class attendance and grade performance. Educational Research Quarterly.

Brotherton, J. A., \& Abowd, G. D. (2004). Lessons learned from eClass: Assessing automated capture and access in the classroom. ACM Transactions on Computer-Human Interaction (TOCHI), 11(2), 121-155.

Bryans Bongey, S., Cizadlo, G., \& Kalnbach, L. (2006). Explorations in course-casting: Podcasts in higher education. Campus-wide information systems, 23(5), 350-367.

Burgan, M. (2006). In defense of lecturing. Change: The Magazine of Higher Learning, 38(6), 30-34.

Chang, S. (2007). Academic perceptions of the use of Lectopia: A University of Melbourne example. Paper presented at the ICT: Providing choices for learners and learning. Proceedings ascilite Singapore 2007.

Chickering, A. W., \& Gamson, Z. F. (1987). Seven principles for good practice in undergraduate education. AAHE bulletin, 3, 7.

Cook, C., Heath, F., \& Thompson, R. L. (2000). A meta-analysis of response rates in web-or internet-based surveys. Educational and psychological measurement, 60(6), 821-836.

Cooke, M., Watson, B., Blacklock, E., Mansah, M., Howard, M., Johnston, A., . . Murfield, J. (2012). Lecture capture: First year student nurses' experiences of a web based lecture technology. Australian Journal of Advanced Nursing, The, 29(3), 14.

Copley, J. (2007). Audio and video podcasts of lectures for campus-based students: production and evaluation of student use. Innovations in education and teaching international, 44(4), 387-399.

Covill, A. E. (2011). College students' perceptions of the traditional lecture method. College Student Journal, 45(1), 92-102. 
Cramer, K. M., Collins, K. R., Snider, D., \& Fawcett, G. (2007). The virtual lecture hall: Utilisation, effectiveness and student perceptions. British Journal of Educational Technology, 38(1), 106-115.

Danielson, J., Preast, V., Bender, H., \& Hassall, L. (2014). Is the effectiveness of lecture capture related to teaching approach or content type? Computers \& education, 72, 121-131.

Deal, A. (2007). Carnegie Mellon teaching with technology white paper: Lecture webcasting. Retrieved July, 7, 2010.

DiPiro, J. T. (2009). Why do we still lecture? American Journal of Pharmaceutical Education, 73(8), 137.

Drouin, M. A. (2014). If you record it, some won't come: Using lecture capture in introductory psychology. Teaching of Psychology, 41(1), 11-19.

Edwards, M. R., \& Clinton, M. E. (2018). A study exploring the impact of lecture capture availability and lecture capture usage on student attendance and attainment. Higher Education, 1-19.

Elliott, C., \& Neal, D. (2016). Evaluating the use of lecture capture using a revealed preference approach. Active Learning in Higher Education, 17(2), 153-167.

Evans, C. (2008). The effectiveness of m-learning in the form of podcast revision lectures in higher education. Computers \& education, 50(2), 491-498.

Feldon, D. F. (2010). Why magic bullets don't work. Change: The Magazine of Higher Learning, 42(2), 15-21.

Francom, J., Ryan, T. G., \& Kariuki, M. (2011). The Effects of Podcasting on College Student Achievement and Attitude. Online Submission.

Germany, L. (2012). Beyond lecture capture: What teaching staff want from web-based lecture technologies. Australasian Journal of Educational Technology, 28(7).

Goldfarb, S., Herr, J., Irrer, J., McKee, S., McLachlan, M., Neal, H., . . . Dey, E. (2008). Mscribe: Piloting and evaluating an automated college classroom web lecture capture system; a final report on technical accomplishments. In: University of Michigan.

Golding, J. M. (2011). The role of attendance in lecture classes: You can lead a horse to water.... Teaching of Psychology, 38(1), 40-42.

Gorissen, P., Van Bruggen, J., \& Jochems, W. (2012). Usage reporting on recorded lectures using educational data mining. International Journal of Learning Technology, 7(1), 2340.

Gosper, M., Green, D., McNeill, M., Phillips, R., Preston, G., \& Woo, K. (2008). The impact of web-based lecture technologies on current and future practices in learning and teaching.

Gosper, M., McNeill, M., Phillips, R., Preston, G., Woo, K., \& Green, D. (2010). Web-based lecture technologies and learning and teaching: a study of change in four Australian universities. ALT-J, 18(3), 251-263.

Greenberg, A., \& Nilssen, A. (2009). The new imperative for lecture capture systems in higher education. Wainhouse Research, LLC, Duxbury, MA, USA.

Griffin, D. K., Mitchell, D., \& Thompson, S. J. (2009). Podcasting by synchronising PowerPoint and voice: What are the pedagogical benefits? Computers \& education, 53(2), 532539.

Groen, J. F., Quigley, B., \& Herry, Y. (2016). Examining the Use of Lecture Capture Technology: Implications for Teaching and Learning. The Canadian Journal for the Scholarship of Teaching and Learning, 7(1), 8.

Gross-Loh, C. (2016). Should colleges really eliminate the college lecture? The Atlantic. 
Guy, R., Byrne, B., \& Dobos, M. (2017). Optional anatomy and physiology e-learning resources: student access, learning approaches, and academic outcomes. Advances in Physiology Education, 42(1), 43-49.

Hadgu, R. M., Huynh, S., \& Gopalan, C. (2016). The use of lecture capture and student performance in physiology. Journal of Curriculum and Teaching, 5(1), 11.

Harley, D., Henke, J., Lawrence, S., McMartin, F., Maher, M., Gawlik, M., \& Muller, P. (2003). Costs, culture, and complexity: An analysis of technology enhancements in a large lecture course at UC Berkeley. Center for Studies in Higher Education.

Harrigan, K. (1995). The SPECIAL system: Self-paced education with compressed interactive audio learning. Journal of Research on Computing in Education, 27(3), 361-370.

Heilesen, S. B. (2010). What is the academic efficacy of podcasting? Computers \& education, 55(3), 1063-1068.

Holbrook, J., \& Dupont, C. (2009). Profcasts and class attendance-Does year in program matter? Bioscience Education, 13(1), 1-4.

Hove, M. C., \& Corcoran, K. J. (2008). If you post it, will they come? Lecture availability in introductory psychology. Teaching of Psychology, 35(2), 91-95.

Kirkpatrick, J. (1990). IN DEFENSE OF LECTURING, OR: IT'S TIME TO CUT DOWN ON TV IN THE CLASSROOM. Paper presented at the Marketing education: Exploring new directions. Proceedings of the western marketing educators' association conference.

Kuh, G. D. (2001). The National Survey of Student Engagement: Conceptual framework and overview of psychometric properties. Retrieved from http://nsse.iub.edu/pdf/psychometric framework 2002.pdf

McFarlin, B. K. (2008). Hybrid lecture-online format increases student grades in an undergraduate exercise physiology course at a large urban university. Advances in Physiology Education, 32(1), 86-91.

McGarr, O. (2009). A review of podcasting in higher education: Its influence on the traditional lecture. Australasian Journal of Educational Technology, 25(3).

McKinney, D., Dyck, J. L., \& Luber, E. S. (2009). iTunes University and the classroom: Can podcasts replace Professors? Computers \& education, 52(3), 617-623.

Molnar, D. (2011). Non-native english language speakers benefit most from the use of lecture capture in medical school. Biochemistry and Molecular Biology Education, 39(6), 416420.

Newman-Ford, L., Fitzgibbon, K., Lloyd, S., \& Thomas, S. (2008). A large-scale investigation into the relationship between attendance and attainment: a study using an innovative, electronic attendance monitoring system. Studies in Higher Education, 33(6), 699-717.

Newton, G., \& McCunn, P. (2015). Student perception of topic difficulty: Lecture capture in higher education. Australasian Journal of Educational Technology, 31(3).

Newton, G., Tucker, T., Dawson, J., \& Currie, E. (2014). Use of lecture capture in higher education-lessons from the trenches. TechTrends, 58(2), 32-45.

Nordmann, E., Calder, C., Bishop, P., Irwin, A., \& Comber, D. (2017). Turn up, tune in, don't drop out: The relationship between lecture attendance, use of lecture recordings, and achievement at different levels of study.

O'Callaghan, F. V., Neumann, D. L., Jones, L., \& Creed, P. A. (2017). The use of lecture recordings in higher education: A review of institutional, student, and lecturer issues. Education and Information Technologies, 22(1), 399-415. 
Owston, R., Lupshenyuk, D., \& Wideman, H. (2011a). Lecture capture in large undergraduate classes: Student perceptions and academic performance. The Internet and Higher Education, 14(4), 262-268.

Owston, R., Lupshenyuk, D., \& Wideman, H. (2011b). Lecture Capture in Large Undergraduate Classes: What Is the Impact on the Teaching and Learning Environment? Online Submission.

Pons, D., Walker, L., Hollis, J., \& Thomas, H. (2012). Evaluation of student engagement with a lecture capture system.

Pursel, B., \& Fang, H. (2012). Lecture capture: Current research and future directions. Schreyer Institute for Teaching Excellence, Pennsy/vania State University.

Revell, K. D. (2013). A comparison of the usage of tablet PC, lecture capture, and online homework in an introductory chemistry course. Journal of Chemical Education, 91(1), 48-51.

Ryan, R. M., \& Deci, E. L. (2000). Intrinsic and extrinsic motivations: Classic definitions and new directions. Contemporary educational psychology, 25(1), 54-67.

Saunders, F., \& Hutt, I. (2015). Enhancing large-class teaching: a systematic comparison of rich-media materials. Higher Education Research \& Development, 34(6), 1233-1250.

Scutter, S., Stupans, I., Sawyer, T., \& King, S. (2010). How do students use podcasts to support learning? Australasian Journal of Educational Technology, 26(2).

Secker, J., Bond, S., \& Grussendorf, S. (2010). Lecture capture: rich and strange, or a dark art?

Snowball, J. (2014). Using interactive content and online activities to accommodate diversity in a large first year class. Higher Education, 67(6), 823-838.

Titsworth, B. S. (2001). Immediate and delayed effects of interest cues and engagement cues on students' affective learning. Communication Studies, 52(3), 169-179.

Toppin, I. N. (2011). Video lecture capture (VLC) system: A comparison of student versus faculty perceptions. Education and Information Technologies, 16(4), 383-393.

Traphagan, T. (2005). Class lecture Webcasting, fall 2004 and spring 2005: A case study. University of Texas, Austin, TX.

Traphagan, T., Kucsera, J. V., \& Kishi, K. (2010). Impact of class lecture webcasting on attendance and learning. Educational technology research and development, 58(1), 19-37.

Vajoczki, S., Watt, S., Marquis, N., \& Holshausen, K. (2010). Podcasts: Are they an effective tool to enhance student learning? A Case Study. Journal of Educational Multimedia and Hypermedia, 19(3), 349-362.

Vajoczki, S., Watt, S., Marquis, N., Liao, R., \& Vine, M. (2011). Students approach to learning and their use of lecture capture. Journal of Educational Multimedia and Hypermedia, 20(2), 195-214.

Veeramani, R., \& Bradley, S. (2008). Insights regarding undergraduate preference for lecture capture, University of Wisconsin-Madison E-Business Institute. In.

Von Konsky, B. R., Ivins, J., \& Gribble, S. J. (2009). Lecture attendance and web based lecture technologies: A comparison of student perceptions and usage patterns. Australasian Journal of Educational Technology, 25(4).

Voort, P. S. V. (2013). A phenomenological exploration of faculty experiences using lecture capture systems. University of Phoenix,

Watt, S., Vajoczki, S., Voros, G., Vine, M., Fenton, N., \& Tarkowski, J. (2014). Lecture capture: An effective tool for universal instructional design? The Canadian Journal of Higher Education, 44(2), 1. 
Wiese, C., \& Newton, G. (2013). Use of Lecture Capture in Undergraduate Biological Science Education. Canadian Journal for the Scholarship of Teaching and Learning, 4(2), 4.

Williams, A. E., Aguilar-Roca, N. M., \& O'Dowd, D. K. (2016). Lecture capture podcasts: differential student use and performance in a large introductory course. Educational technology research and development, 64(1), 1-12.

Woo, K., Gosper, M., McNeill, M., Preston, G., Green, D., \& Phillips, R. (2008). Web-based lecture technologies: blurring the boundaries between face-to-face and distance learning. $A L T-J, 16(2), 81-93$.

Yu, P. T., Wang, B. Y., \& Su, M. H. (2015). Lecture capture with real-time rearrangement of visual elements: impact on student performance. Journal of Computer Assisted Learning, 31(6), 655-670. 
Supplementary Table 1: Details of the questions within the student survey. ${ }^{*}$ Reversed score items

\begin{tabular}{|c|c|}
\hline Survey Section/Question & Response Options \\
\hline \multicolumn{2}{|l|}{ Participant Characteristics: } \\
\hline Please indicate your gender. & Male/Female/Prefer not to say \\
\hline Please indicate whether English is your first language. & Yes/No \\
\hline $\begin{array}{l}\text { Under the Equality Act, a disability is defined as a physical or mental impairment which has a substantial and long-term } \\
\text { adverse effect on a person's ability to carry out normal day to day activities. Do you consider yourself to have a disability? }\end{array}$ & Yes/No/Prefer not to say \\
\hline Please indicate the faculty in which you are studying. & $\begin{array}{l}\text { Nine faculties/schools of host } \\
\text { university listed }\end{array}$ \\
\hline Please indicate the type of qualification you are currently working towards. & $\begin{array}{l}\text { Undergraduate degree/ } \\
\text { Postgraduate taught degree }\end{array}$ \\
\hline Which of the following type of learning event do you have as part of your current programme? Select all that apply. & $\begin{array}{l}\text { Lectures/Seminars or } \\
\text { tutorials/Practicals or workshops }\end{array}$ \\
\hline $\begin{array}{l}\text { In a typical study week at university, how many hours of contact time do you have (i.e. time in any of the learning events } \\
\text { listed previously, that is seminars, tutorials, lectures, workshops, practical classes or demonstrations)? }\end{array}$ & $1-8 / 9-16 / 17-24 / 25-32 / 33-40$ \\
\hline
\end{tabular}




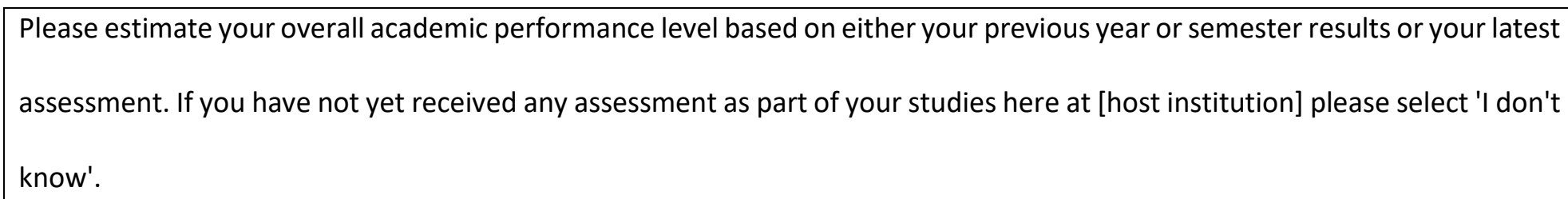

\section{Perception of lectures \& lecture capture:}

If you have more than one of the types of learning event listed, please rank them in order of the value you place on them

within your programme of study so that the highest value learning event is ranked as 1 and the lowest is ranked as 3.

Ordering of: Lectures/

Seminars or tutorials/ Practicals or

*Learning outcomes can be broadly divided into four categories:

- Knowledge and understanding -learning outcomes requiring students to demonstrate or explain knowledge of key concepts or theories.

- Cognitive skills - learning outcomes requiring students to demonstrate particular abilities, for example, using data or recognising limitations of a particular approach.

- Key skills - learning outcomes relating to study skills (such as locating information online) or communication skills.

- Professional and practical skills - learning outcomes relating to professional practice in some way. For example, for a scientist, this may be designing and conducting an experiment.

Please indicate to the extent to which you feel lectures are effective in helping you achieve each type of learning outcome.

*Please indicate the extent to which you agree with the following statement:

"My active participation and interaction in the lecture determines what I, and others, can learn from it" 


\begin{tabular}{|c|c|}
\hline *When attending live lectures please rate the typical amount of information delivered in the lecture. & $\begin{array}{l}1=\text { far too much } \\
5=\text { far too little }\end{array}$ \\
\hline Please rate the ease with which you feel able to make notes that support your learning in a typical live lecture. & $\begin{array}{l}1 \text { = extremely easy } \\
7 \text { = extremely difficult }\end{array}$ \\
\hline *Please indicate your overall perception of lecture capture. & $\begin{array}{l}1=\text { Very positive } \\
5=\text { Very negative }\end{array}$ \\
\hline $\begin{array}{l}\text { *Please rate the extent to which you agree with the following statements. } \\
\text { i) Using lecture capture allows me to make more detailed notes } \\
\text { ii) Using lecture capture allows me to pace my own learning } \\
\text { iii) Using lecture capture allows me more independence in my study }\end{array}$ & $\begin{array}{l}1 \text { = Strongly agree } \\
7=\text { Strongly disagree }\end{array}$ \\
\hline $\begin{array}{l}\text { *Please rate your agreement with the following statements about the potential impact of lecture capture on the live lecture. } \\
\text { The presence of lecture capture: } \\
\text { i) makes me less likely to ask questions in the live lecture } \\
\text { ii) alters the lecturers' teaching style e.g. moving around less } \\
\text { iii) alters the material delivered, for example, use of anecdotes or specific images and multimedia }\end{array}$ & $\begin{array}{l}1 \text { = Strongly agree } \\
7 \text { = Strongly disagree }\end{array}$ \\
\hline \multicolumn{2}{|l|}{ Using Lecture Capture: } \\
\hline $\begin{array}{l}\text { Please indicate your frequency of use of lecture capture in a typical week during the teaching term. This may be watching } \\
\text { segments or entire lectures. }\end{array}$ & $\begin{array}{l}\text { Daily/4-6 times a week/2-3 times } \\
\text { a week/Once a week/ Never }\end{array}$ \\
\hline
\end{tabular}




\begin{tabular}{|c|c|}
\hline $\begin{array}{l}\text { Please indicate your frequency of use of lecture capture in a typical week in which you are predominantly revising for an exam } \\
\text { or completing other assessment. This may be watching segments or entire lectures. }\end{array}$ & $\begin{array}{l}\text { Daily/4-6 times a week/2-3 times } \\
\text { a week/Once a week/ Never }\end{array}$ \\
\hline $\begin{array}{l}\text { *Please indicate the frequency with which you use lecture capture for each of the following purposes. } \\
\text { i) To review lectures that I attended live to make detailed notes } \\
\text { ii) To review lectures that I attended live to help understand specific segments of difficult material } \\
\text { iii) To review lectures I attended live during my revision or preparation of coursework } \\
\text { iv) To review lectures that I did not attend to make detailed notes } \\
\text { v) To review lectures that I did not attend during revision or preparation of coursework }\end{array}$ & $\begin{array}{l}1=\text { Always } \\
2=\text { Most of the time } \\
3=\text { About half the time } \\
4=\text { Sometimes } \\
5=\text { Never }\end{array}$ \\
\hline *Please indicate your typical lecture attendance in an average week. & $\begin{array}{l}1=\text { Attend all lectures } \\
5=\text { Attend no lectures }\end{array}$ \\
\hline $\begin{array}{l}\text { *Please indicate the importance of each factor below on whether you choose to attend a live lecture. } \\
\begin{array}{l}\text { i) cost of travelling to the lecture } \\
\text { ii) time taken to travel relative to teaching time } \\
\text { iii) early or late scheduling of lecture } \\
\text { iv) other academic commitments e.g. coursework deadline } \\
\text { v) other academic-related commitments e.g. preparation for interviews/placements } \\
\text { vi) family commitments } \\
\text { vii) employment commitments } \\
\text { viii) availability of online resources such as slides to support learning for the lecture } \\
\text { ix) availability of lecture capture for the lecture }\end{array}\end{array}$ & $\begin{array}{l}1=\text { Extremely important } \\
5=\text { Not at all important }\end{array}$ \\
\hline If you do miss a lecture and lecture capture is available when are you most likely to watch it? & $\begin{array}{l}\text { As soon as possible and before the } \\
\text { next lecture for the }\end{array}$ \\
\hline
\end{tabular}




\begin{tabular}{|c|c|}
\hline & $\begin{array}{l}\text { module/Within term time but not } \\
\text { necessarily before the next } \\
\text { lecture for the module/At the end } \\
\text { of teaching during the revision } \\
\text { period/I am unlikely to ever watch } \\
\text { the lecture capture }\end{array}$ \\
\hline \multicolumn{2}{|l|}{ Satisfaction and technical awareness } \\
\hline $\begin{array}{l}\text { *Please indicate your satisfaction with the following properties of lecture capture. } \\
\text { i) audio quality } \\
\text { ii) video quality (if applicable) } \\
\text { iii) delay between live event and availability } \\
\text { iv) ease of access }\end{array}$ & $\begin{array}{l}1=\text { Extremely satisfied } \\
5=\text { Extremely dissatisfied }\end{array}$ \\
\hline Which of the following features of lecture capture are you aware of (select all that apply)? & $\begin{array}{l}\text { Variable playback speed/ } \\
\text { pause/restart facility/ } \\
\text { bookmarking/creation and } \\
\text { download study notes/ mobile } \\
\text { app usage/none of these }\end{array}$ \\
\hline
\end{tabular}




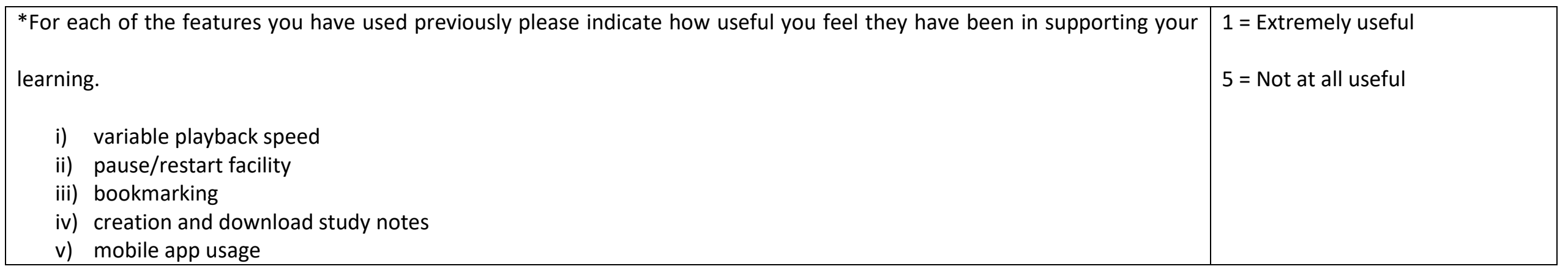

Supplementary Table 2: Details of the questions within the staff survey. ${ }^{*}$ Reversed score items

\begin{tabular}{|l|l|}
\hline Survey Section/Question & Response Options \\
\hline Participant Characteristics: & Male/Female/Prefer not to say \\
\hline Please indicate your gender. & Yes/No \\
\hline Please indicate whether English is your first language. & university listed \\
\hline $\begin{array}{l}\text { Please indicate the type of programme you lecture on. If you lecture on multiple programmes of study, please select the one } \\
\text { for which you do the majority of your lecturing. }\end{array}$ & Undergraduate degree/ \\
\hline
\end{tabular}




\begin{tabular}{|c|c|}
\hline Please indicate your current role at King's. & $\begin{array}{l}\text { Teaching fellow/Lecturer/Senior } \\
\text { Lecturer/Reader/Professor }\end{array}$ \\
\hline $\begin{array}{l}\text { Which of the following types of learning event do you have in the modules/programmes you contribute lectures to? Note } \\
\text { that these may not be sessions you actually deliver but they may be part of the same module/programme as your lectures. } \\
\text { Select all that apply. }\end{array}$ & $\begin{array}{l}\text { Lectures/Seminars or } \\
\text { tutorials/Practicals or workshops }\end{array}$ \\
\hline \multicolumn{2}{|l|}{ Perception of lectures \& lecture capture: } \\
\hline $\begin{array}{l}\text { *For each of the following learning events, please indicate how useful you feel they are for the students' learning experience. } \\
\text { i) Lectures } \\
\text { ii) Seminars or tutorials } \\
\text { iii) Practicals or workshops }\end{array}$ & $\begin{array}{l}1=\text { Extremely useful } \\
5=\text { Extremely useless }\end{array}$ \\
\hline $\begin{array}{l}\text { *Learning outcomes can be broadly divided into four categories: } \\
\text { - Knowledge and understanding -learning outcomes requiring students to demonstrate or explain knowledge of key } \\
\text { concepts or theories. } \\
\text { - Cognitive skills - learning outcomes requiring students to demonstrate particular abilities, for example, using data or } \\
\text { recognising limitations of a particular approach. } \\
\text { - Key skills - learning outcomes relating to study skills (such as locating information online) or communication skills. } \\
\text { Professional and practical skills - learning outcomes relating to professional practice in some way. For example, for a } \\
\text { slease indicate to the extent to which you feel lectures are effective in helping you achieve each type of learning outcome. }\end{array}$ & $\begin{array}{l}1=\text { Extremely effective } \\
5=\text { Not at all effective }\end{array}$ \\
\hline *Please indicate the extent to which you agree with the following statement: & $\begin{array}{l}1 \text { = Strongly agree } \\
7 \text { = Strongly disagree }\end{array}$ \\
\hline
\end{tabular}




\begin{tabular}{|c|c|}
\hline "Active participation by students in the lecture determines what they can learn from it." & \\
\hline *Please indicate your level of comfort delivering lectures (in the absence of any capture). & $\begin{array}{l}1 \text { = Extremely Comfortable } \\
5=\text { Extremely Uncomfortable } \\
\text { (N/A option) }\end{array}$ \\
\hline *Please indicate your overall perception of lecture capture. & $\begin{array}{l}1=\text { Very positive } \\
5=\text { Very negative }\end{array}$ \\
\hline $\begin{array}{l}\text { *Please rate the extent to which you agree with the following statements. } \\
\text { iv) Using lecture capture allows students to make more detailed notes } \\
\text { v) Using lecture capture allows students to pace their own learning } \\
\text { vi) Using lecture capture allows students more independence in their study }\end{array}$ & $\begin{array}{l}1 \text { = Strongly agree } \\
7 \text { = Strongly disagree }\end{array}$ \\
\hline $\begin{array}{l}\text { *Please rate your agreement with the following statements about the potential impact of lecture capture on the live lecture. } \\
\text { The presence of lecture capture: } \\
\text { iv) makes students less likely to ask questions in the live lecture } \\
\text { v) alters my teaching style e.g. moving around less } \\
\text { vi) alters the material delivered, for example, use of anecdotes or specific images and multimedia }\end{array}$ & $\begin{array}{l}1 \text { = Strongly agree } \\
7 \text { = Strongly disagree }\end{array}$ \\
\hline *Please indicate your comfort in delivering a captured lecture. & $\begin{array}{l}1=\text { Extremely Comfortable } \\
5=\text { Extremely Uncomfortable }\end{array}$ \\
\hline What additional resources do you provide for students to support their learning from lectures after the live event? & $\begin{array}{l}\text { Copies of slides/Lecture } \\
\text { notes/Interactive activities e.g. }\end{array}$ \\
\hline
\end{tabular}




\begin{tabular}{|c|c|c|}
\hline & & $\begin{array}{l}\text { quizzes/Related forum } \\
\text { discussions/Reading lists/None of } \\
\text { the above }\end{array}$ \\
\hline \multicolumn{3}{|c|}{ Using Lecture Capture: } \\
\hline $\begin{array}{l}\text { Please in } \\
\text { records o } \\
\text { i) } \\
\text { ii) }\end{array}$ & $\begin{array}{l}\text { Please indicate typical lecture attendance for your lectures in an average week. This can be based on actual attendance } \\
\text { records or, if you do not keep these, your own perception. }\end{array}$ & $\begin{array}{l}\text { All or nearly all attend/Most } \\
\text { attend }(\sim 75 \%) / \text { Around half } \\
\text { attend/Some attend }(\sim 25 \%) / \text { Few } \\
\text { or none attend. }\end{array}$ \\
\hline $\begin{array}{l}\text { *Please ir } \\
\text { x) } \\
\text { xi) } \\
\text { xii) } \\
\text { xiii) } \\
\text { xiv) } \\
\text { xv) } \\
\text { xvi) } \\
\text { xvii) } \\
\text { xviii) }\end{array}$ & $\begin{array}{l}\text { icate the importance you believe each factor below has on whether students choose to attend a live lecture. } \\
\text { cost of travelling to the lecture } \\
\text { time taken to travel relative to teaching time } \\
\text { early or late scheduling of lecture } \\
\text { other academic commitments e.g. coursework deadline } \\
\text { other academic-related commitments e.g. preparation for interviews/placements } \\
\text { family commitments } \\
\text { employment commitments } \\
\text { availability of online resources such as slides to support learning for the lecture } \\
\text { availability of lecture capture for the lecture }\end{array}$ & $\begin{array}{l}1=\text { Extremely important } \\
5=\text { Not at all important }\end{array}$ \\
\hline \multicolumn{3}{|c|}{ Satisfaction and technical awareness } \\
\hline \multicolumn{2}{|c|}{ *Please indicate your satisfaction with the following properties of lecture capture. } & $\begin{array}{l}1=\text { Extremely satisfied } \\
5=\text { Extremely dissatisfied }\end{array}$ \\
\hline
\end{tabular}




\begin{tabular}{|c|c|}
\hline $\begin{array}{ll}\text { vii) delay between live event and availability } \\
\text { viii) ease of access }\end{array}$ & \\
\hline Which of the following features of lecture capture are you aware of (select all that apply)? & $\begin{array}{l}\text { Variable playback speed/ } \\
\text { pause/restart facility/ } \\
\text { bookmarking/creation and } \\
\text { download study notes/ mobile } \\
\text { app usage/none of these }\end{array}$ \\
\hline $\begin{array}{l}\text { *For each of the features please indicate how useful you feel they could be in supporting learning. } \\
\text { vi) variable playback speed } \\
\text { vii) pause/restart facility } \\
\text { viii) bookmarking } \\
\text { ix) creation and download study notes } \\
\text { x) mobile app usage }\end{array}$ & $\begin{array}{l}1=\text { Extremely useful } \\
5=\text { Not at all useful }\end{array}$ \\
\hline
\end{tabular}

